\title{
Organization around the dnaA gene of Streptococcus pneumoniae
}

\author{
Anne-Marie Gasc, ${ }^{1}$ Philippe Giammarinaro, ${ }^{1}$ Stefan Richter ${ }^{2} \dagger$ \\ and Michel Sicard ${ }^{1}$
}

Author for correspondence: Anne-Marie Gasc. Tel: +330561335971. Fax: + 330561335886 . e-mail : gasc@ibcg.biotoul.fr

1 Laboratoire de Microbiologie et de Génétique Moléculaire du CNRS, Université Paul Sabatier, 118 route de Narbonne, 31062 Toulouse Cedex, France

2 Max-Planck-Institut für Molekulare Genetik Ihnestr. 73, D-14195 Berlin, Germany

\begin{abstract}
The dnaA gene region of Streptococcus pneumoniae was cloned and sequenced. A tRNA gene, seven ORFs and three DnaA box clusters were identified. The order of the genes and intergene regions found was tRNAArg. orf1-DnaA box cluster 3-htrA-spooJ-DnaA box cluster 2-dnaA-DnaA box cluster 1-dnaN-orfX-orfY. Five ORFs are homologous to known bacterial genes. The tRNA ${ }^{A r g}$ gene and orf1, also called orfL, have already been described in pneumococci and have been reported to be preceded by the competence regulation locus comCDE. In Escherichia coli, htrA encodes a serine protease. In Bacillus subtilis, spooJ plays a role in sporulation and partition. dnaA encodes an initiator replication protein, very well conserved in several bacteria and dnaN encodes the $\beta$ subunit of DNA polymerase III in $E$. coli. The function of orfX is unknown. The $\mathrm{N}$-terminal part of another reading frame, orfY, revealed high homology with a GTP-binding protein. DnaA box clusters were found upstream and downstream from dnaA. The presence of two such clusters suggests that the chromosomal origin of $S$. pneumoniae is located within this region. The position of $\mathrm{dnaA}$, and therefore the putative origin of replication, were localized on the physical map of $S$. pneumoniae.
\end{abstract}

Keywords: Streptococcus pneumoniae, dnaA, DnaA boxes, $\operatorname{dna} N$, $\operatorname{tr} A$, replication origin

\section{INTRODUCTION}

The DnaA protein is the essential initiator of chromosome replication in eubacteria. It recognizes the replication origin by binding to $9 \mathrm{bp}$ sequences known as DnaA boxes with the consensus sequence TTAT(C/A)CACA (Ogasawara et al., 1990; Ogasawara \& Yoshikawa, 1992; Fujita et al., 1990, 1992; Schaper \& Messer, 1995). The interaction of the DnaA protein with the DnaA box plays a central role in the initiation of chromosome replication. Different organization around $d n a A$ genes has been reported in several species (Zweiger \& Shapiro, 1994; Richter \& Messer, 1995). However, at least six genes, rnpA, rpmH, dnaA, dnaN, recF and gyrB, are conserved in Escherichia coli and Bacillus subtilis (Ogasawara et al., 1985). Even Mycoplasma

†Present address: University of Chicago, Department of Molecular Genetics and Cell Biology, 920 East 58th Street, Chicago, IL 60637, USA.

Abbreviation: SD, Shine-Dalgarno.

The GenBank accession number for the sequence reported in this paper is AF000658. capricolum, a species with a genome size of approximately $700 \mathrm{~kb}$, has at least two conserved genes $d n a A: r p m H$ and dnaN (Ogasawara \& Yoshikawa, 1992). DnaA boxes are located near dnaA in several bacteria or elsewhere in bacteria such as $E$. coli or Synechococcus sp. (Liu \& Tsinoremas, 1996).

Streptococcus pneumoniae is a pathogenic bacterium responsible for a high level of mortality in patients of all ages. Therefore, it is important to know how its replication is regulated. We have constructed a physical map of the $S$. pneumoniae chromosome showing that it is circular and $2 \cdot 2 \mathrm{Mb}$ in size (Gasc et al., 1991). However, the origin of replication has not yet been determined. The aim of this work was to clone and sequence the $d n a A$ gene and the neighbouring genes in this bacterium. The $d n a A$ region was localized on the physical map of the chromosome. The sequence of approximately $6000 \mathrm{bp}$ around the $d n a \mathrm{~A}$ gene is presented showing seven ORFs, including $d n a A$ and the tRNA $^{\text {Arg }}$ gene. A comparison of the predicted amino acid sequences from these ORFs with known gene products from other species is given. Several DnaA 
boxes were identified downstream and upstream from $d n a A$, defining a putative replication origin.

\section{METHODS}

Bacterial strains, growth conditions and DNA preparation. The pneumococcal strain used in this study is a derivative of R6, called 801 (Lefevre et al., 1979). The culture media have been described elsewhere (Claverys et al., 1980). Cultures were incubated at $37^{\circ} \mathrm{C}$ without aeration. Preparation of DNA and transformation procedures have been described previously (Martin et al., 1985; Gasc et al., 1995).

Determination of the nucleotide sequence. The fragments used are described in the text. The PCR fragments were obtained using the Tub polymerase from Amersham by 25

\section{Table 1. Primers used to sequence the insert}

The primers in the upper part are localized on one strand; the primers in the lower part are on the complementary strand. T45, B39 and B40 were synthesized using fragment A containing part of the $d n a A$ gene. T31 and T70 were synthesized using the sequence of a $\lambda$ Zap clone determined from T3 or $\mathrm{T} 7$ universal primers.

\begin{tabular}{|c|c|c|}
\hline Primer & Sequence $\left(5^{\prime}-3^{\prime}\right)$ & Localization \\
\hline $\mathrm{T} 31$ & GGG GAA TCC CTG CTG AAT CGT AAA & 127 \\
\hline T32 & CCT TAT CTG GTG TTT TTT CAT C & 456 \\
\hline $\mathrm{T} 33$ & CAC AAT TTC AAA AGA GTT ATC CA & 670 \\
\hline $\mathrm{T} 33 \mathrm{a}$ & CAG TAA TTC AAA CAT ATG GAG GC & 750 \\
\hline T34 & GGC TGT TAA CAA AGT AAA AGA TGC TG & 965 \\
\hline $\mathrm{T} 35$ & CTT TCT CTG ATA TTG CTG TCG CC & 1222 \\
\hline $\mathrm{T} 36$ & CCT GCA AAT GAT GCT ATC & 1581 \\
\hline T37 & GCT TTG GGA ATC CAG ATG G & 1644 \\
\hline T38 & CGG GAA AGA AGA AAC TAC CTC & 1898 \\
\hline T39 & CAA GAG ATG ATG GTC CCA GTC C & 2265 \\
\hline $\mathrm{T} 40$ & CAA CGG ATT ATG AAG AAG AT & 2541 \\
\hline T41 & CTA TCT AAA AAA GGC AG & 2691 \\
\hline $\mathrm{T} 42$ & CTT GCT ATC TAT GGT AAA ATA TC & 2924 \\
\hline $\mathrm{T} 43$ & ACA AGG TGA AGA AGC TAC AA & 3250 \\
\hline $\mathrm{T} 44$ & AAC GCT ATT GGA AAT GAA ATT C & 3482 \\
\hline $\mathrm{T} 45$ & AAC AGA TTG TCC TAA CGA GTG ATC G & 3723 \\
\hline T46 & GCC CGT CAA GTA GCC ATG TA & 4163 \\
\hline T47 & CCA CAG ATT TCA CAG ACT C & 4439 \\
\hline $\mathrm{T} 48$ & GGT TCG ATC CTT CTT GAA G & 4723 \\
\hline T49 & GCC GTT CTC TAC GCG AAT TTT CA & 5120 \\
\hline T50 & GGT TAC TGG TGA AGA TTT G & 5463 \\
\hline T51 & GGT AAA AAG GCT AAT CGT TGG & 5771 \\
\hline $\mathrm{T} 70$ & AAT AGT CGC AAA TGG GTA G & 6096 \\
\hline $\mathrm{T} 71$ & CAT ATC GCC CCA TCA TGA CAA C & 5867 \\
\hline $\mathrm{T} 72$ & GTA AAT GGA CGA ACA GCT GAG & 5579 \\
\hline $\mathrm{T} 73$ & GTT GGA ATC AAG CGA TCT G & 5279 \\
\hline B36 & GGG TAA TTT CTG ATT TGC CAC TGG & 4849 \\
\hline B37 & GTA ATA TTT AAT GCT TGT AG & 4559 \\
\hline B38 & CCC CCA AAT TCC TTC CC & 4239 \\
\hline B39 & AAT ACA TGG CTA CTT GAC GGG CC & 4184 \\
\hline $\mathrm{B} 40$ & CGT GAC AAG CCT CTC CTC GAG CCC & 3790 \\
\hline B41 & AGT CTT ACC AAG GCC TGG & 3472 \\
\hline B42 & GTG GGG TGT TAT TTC AGC G & 3214 \\
\hline B43 & CAC AGG TTG GGG ATA AAA GAA GA & 2873 \\
\hline B44 & GCT GTT TCT TTT GTT TTT TCT & 2616 \\
\hline B45 & GGG TGA ATC GGC CTC TAC GAG & 2371 \\
\hline B46 & CAC ATC TTT TCT CTT ATG TAA AGC & 2002 \\
\hline B47 & GAA TAT TGA GTC TTC TGA TGT CGC & 1710 \\
\hline B48 & CAT ATT CAG AAC CTA ACG GGC & 1353 \\
\hline B49 & CAG TAT CAT CAT TCC CAA AGA CGC & 1053 \\
\hline B50 & GCC TCC ATA TGT TTG AAT TAC TG & 772 \\
\hline B51 & GGT ATC GCA GAG TAT TCC AAA ACG & 540 \\
\hline
\end{tabular}




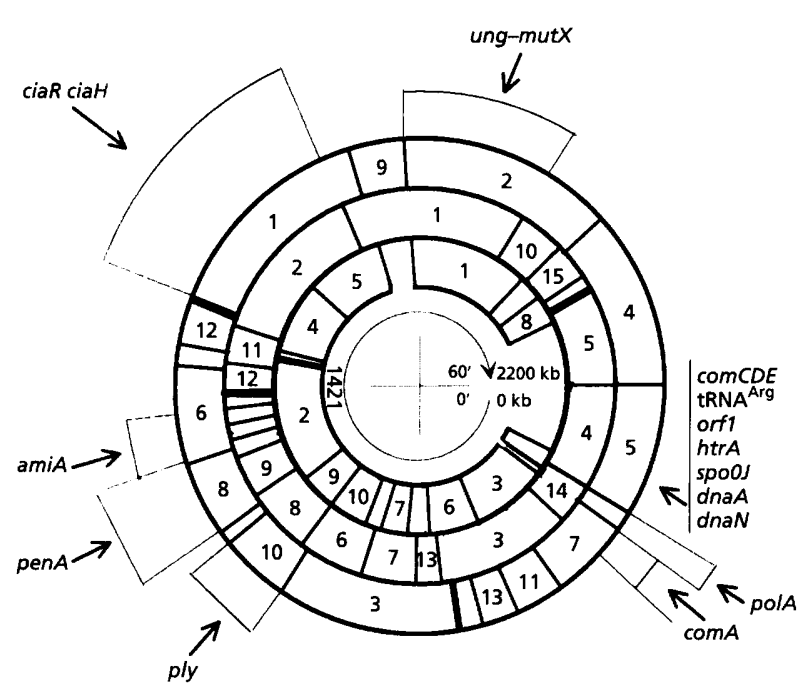

Fig. 1. Position of the $d n a A$ region in the physical map of the S. pneumoniae R6 chromosome. The outer circle represents Smal fragments, the middle circle Apal fragments and the inner circle Sacll fragments. Spaces between fragments indicate contiguity has not been established.

cycles of $30 \mathrm{~s}$ at $94^{\circ} \mathrm{C}, 2 \mathrm{~min}$ at $56^{\circ} \mathrm{C}$ and $1 \mathrm{~min}$ at $72{ }^{\circ} \mathrm{C}$ following the manufacturer's recommendations. The fragments were purified using the Wizard Purification Kit (Promega). Sequencing was done using the Circumvent Thermal Cycle Sequencing Kit (Biolabs) or performed at Euro Sequence Genes Services, Evry, France, on an ABI377 Sequencer using the PRISM Dye Terminator Cycle Sequencing Ready Reaction Kit with AmpliTaq DNA polymerase (Applied Biosystems). Oligonucleotide primers and their positions are listed in Table 1.

Electrophoresis and hybridization. Southern blot hybridizations (Southern, 1975) were performed essentially as described by Sambrook et al. (1989). Field inversion gel electrophoresis has been described by Kauc et al. (1989). Fragments were labelled by the Megaprime Labelling Kit (Amersham).

\section{RESULTS AND DISCUSSION}

\section{Cloning and sequencing of the $d n a A$ region}

Degenerate oligonucleotide primers were deduced from two highly conserved regions of the DnaA protein (foreward primer 5' GARGARTTYTTYCAYACNTTYAAY; reverse primer $5^{\prime}$ ACWGTHGTRTGRTCYCTWCCWCC). PCR using the degenerate primers and chromosomal DNA of $S$. pneumoniae was carried out as described previously (Richter \& Messer, 1995). A PCR fragment of $531 \mathrm{bp}$ (fragment A) was obtained and sequenced. The deduced amino acid sequence showed a high degree of homology to the corresponding region of known DnaA proteins, suggesting that this fragment belongs to the pneumococcal $d n a A$ gene. Fragment A, labelled with $\left[\alpha_{-}{ }^{32} \mathrm{P}\right] \mathrm{dATP}$, was hybridized to $S m a \mathrm{I}$, ApaI and SacII fragments of the S. pneumoniae chromosome, separated by field inversion gel electrophoresis. Fig. 1 shows the position of the $d n a A$ gene on the previously published physical map of $S$. pneumoniae (Gasc et al., 1991).

To clone the region around the $d n a A$ gene, we screened a S. pneumoniae DNA $\lambda$ Zap (Short et al., 1988) library constructed by B. Martin (this laboratory) for the presence of fragment A. We selected a clone ( $\lambda$ ZapA) that hybridized with fragment $\mathrm{A}$. To determine the size of the cloned fragment, $\lambda$ ZapA DNA was digested with Bam HI and SmaI which cut the polylinker on both sides of the fragment. A $6 \mathrm{~kb}$ fragment was obtained. To localize fragment $\mathrm{A}$ on the $6 \mathrm{~kb}$ fragment, we generated PCR products using the universal primers $\mathrm{T} 3$ or $\mathrm{T} 7$ and one of the three primers T45, B39 or B40 (Table 1) synthesized using the pneumococcal fragment A sequence. The localization of fragment $A$ on the insert indicated that it carries sequences both downstream and upstream from the $d n a A$ gene.

To determine the start point of the pneumococcal DNA sequence at both ends of the insert, we sequenced the PCR products prepared as described above. We synthesized new oligonucleotides (T31 and T70, Table 1)

Table 2. Genes of the insert

\begin{tabular}{|c|c|c|c|c|}
\hline Gene & $\begin{array}{l}\text { Localization } \\
\text { of the gene }\end{array}$ & $\begin{array}{l}\text { Size of the } \\
\text { protein (aa) }\end{array}$ & Putative promoter & $\begin{array}{c}\text { Putative SD } \\
\text { sequence }^{*}\end{array}$ \\
\hline Consensus & & & TTGACA TnTGnTATAAT & UAAGGAGGUG \\
\hline $\mathrm{tRNA}^{\mathrm{Arg}}$ & $72-1$ & & & \\
\hline orf1 or orf $L$ & $594-115$ & & & \\
\hline btrA & $765-1955$ & 397 & gTGtaA TaaGtTATAAT & GGAGG (5) \\
\hline spooJ & $2016-2771$ & 252 & TTGACA aagctTtacAT & GTG (7) \\
\hline $\operatorname{dnaA}$ & $2987-4345$ & 453 & TgGAaA TaTGgTAaAAT & AAGGAGG (8) \\
\hline$d n a N$ & $4507-5640$ & 378 & TTcACA acTat ATctT & AAGGAG (5) \\
\hline orfX & $5707-5899$ & 64 & TTGAgc TaTGaTATAAT & AAGGAG (6) \\
\hline orf $Y$ & $\begin{array}{l}5986-6098 \\
\text { insert end }\end{array}$ & Not known & TTagCA TgTGtTATAAT & GGAG (10) \\
\hline
\end{tabular}

* The number of nucleotides between the SD sequence and the initiation codon is indicated in parentheses. 
Domain $\mid>$

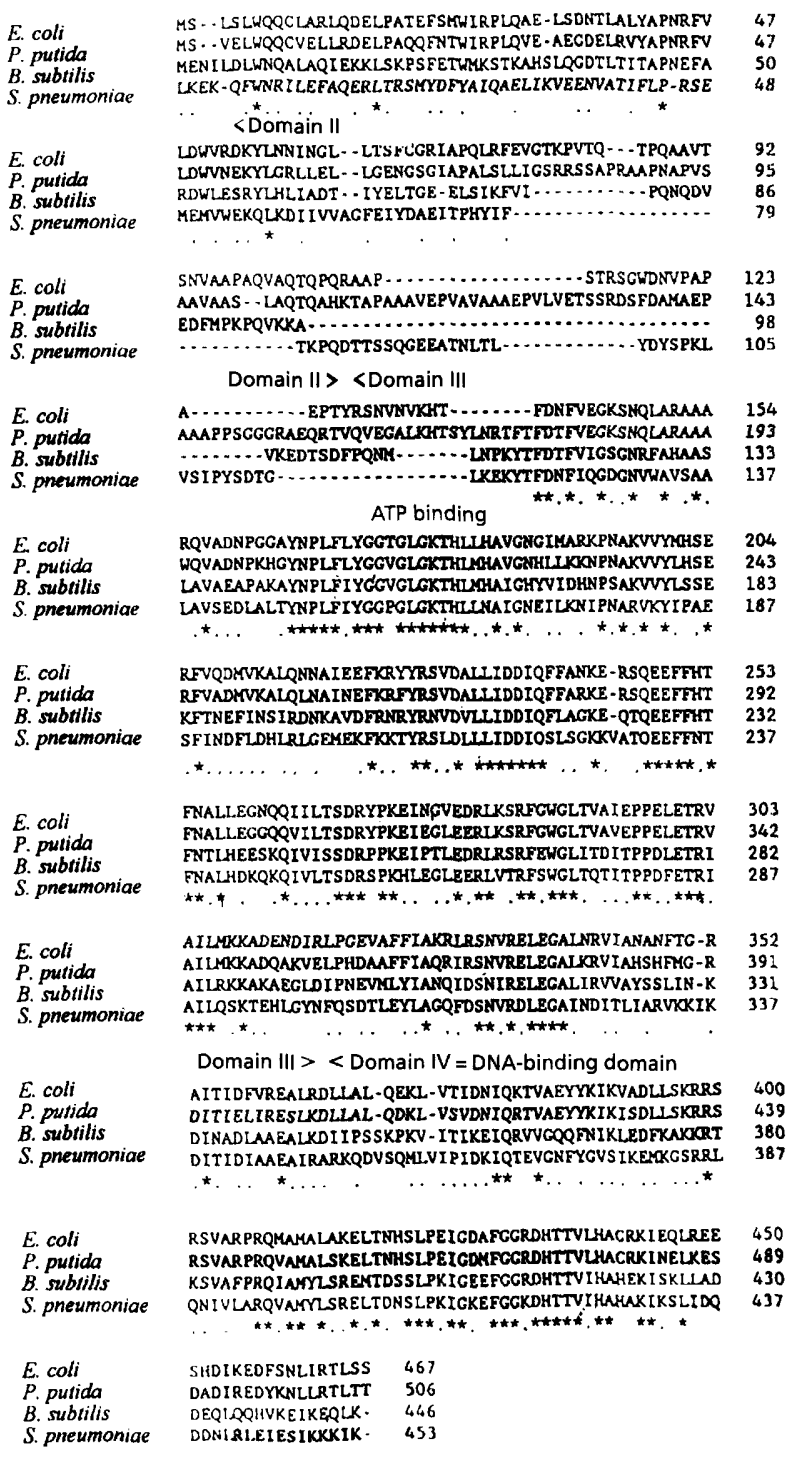

Fig. 2. Sequence alignment of four DnaA proteins from $E$. coli, $P$. putida, $B$. subtilis and $S$. pneumoniae. The alignment was done using PCGENE. Division in domains I-IV was defined according to Yoshikawa \& Ogasawara (1991). The ATP-binding site and DNA-binding domain are shown. Asterisks indicate identical amino acids; dots indicate similar amino acids.

based on pneumococcal DNA sequences. The next step was PCR amplification of pneumococcal DNA from strain 801 using T31 and B39 primers to generate a $4 \mathrm{~kb}$ fragment. Another PCR amplification using T45 and T70 generated a $2 \cdot 2 \mathrm{~kb}$ fragment. The PCR sequences were then determined.

\section{Sequence analysis}

Putative ORF, promoter and Shine-Dalgarno (SD) sequences. Amino acid sequences were deduced from the nucleotide sequences. We found seven putative ORFs on the $\lambda$ ZapA insert (Table 2). A comparison with database sequences revealed some homologies. The S. pneumoniae genes were named according to their similarity to known genes. In the $6 \mathrm{~kb}$ fragment, six putative promoters were defined using the criteria proposed for S. pneumoniae by Sabelnikov et al. (1995) (Table 2). The prokaryotic $\mathrm{mRNA}$ ribosome-binding site (RBS) usually contains part or all of the SD sequence UAAGGAGGU (Shine \& Dalgarno, 1974) and the spacing between the $\mathrm{SD}$ sequence and the initiation codon varies from 5 to $10 \mathrm{nt}$, as usually observed (Singer et al., 1981; Chen et al., 1994). According to these criteria, six putative SD sequences were proposed (Table 2).

dnaA gene. The complete sequence of the DnaA protein is known for several bacteria. The size of the DnaA proteins varies from 437 to $656 \mathrm{aa}$. The length of the $S$. pneumoniae deduced DnaA protein is 453 aa (Table 2, Fig. 2).

The amino acid sequences of four DnaA proteins were compared (Fig. 2). The level of identity between $S$. pneumoniae DnaA and that of $B$. subtilis, another Gram-positive bacterium, is the highest $(38.8 \%)$. The level of identity with the DnaA proteins of Pseudomonas putida and E. coli is 33.3 and $32.5 \%$, respectively. DnaA proteins were divided into four domains with different degrees of conservation (Fujita et al., 1992). These domains are conserved in $S$. pneumoniae. The $\mathrm{N}$ terminal domain I, with moderate conservation, is followed by domain II, variable in sequence and length. The highly conserved domain III contains an ATPbinding site. The C-terminal domain IV, the DNAbinding domain (Yoshikawa \& Ogasawara, 1991; Roth \& Messer, 1995) is also highly conserved. A TTG codon was identified near the ribosome-binding site and it seems the best candidate to be the start codon. The secondary structure was also conserved compared to the DnaA protein predicted by Schaper \& Messer (1997). DnaA from $S$. pneumoniae could therefore be included among the other proteins of the DnaA family.

The unusual initiation codon, TTG, has also been found in E. coli and in B. subtilis (Ogasawara et al., 1994) where it is the third most frequent initiation codon after ATG and GTG. It is noteworthy that it has been recently reported that the start codon for $d n a A$ genes in Mycobacterium smegmatis, $M$. leprae and M. tuberculosis is also TTG (Salazar et al., 1996).

DnaA boxes. The DnaA protein binds specifically to the DnaA box TTAT(C/A)CACA and closely related sequences (Yoshikawa \& Ogasawara, 1991; Fuller et al., 1984; Schaefer \& Messer, 1991; Fujita et al., 1992). Interaction of DnaA with the DnaA boxes of the origin forms the initiation complex. DnaA boxes have been identified in the intragenic region flanking $d n a A$ in most bacteria studied. In S. pneumoniae we found six DnaA boxes upstream (cluster 2) and three downstream (cluster 1) of dnaA. This seems to be a common feature of the chromosomal origins in Gram-positive bacteria (Ogasawara et al., 1985; Fujita et al., 1989, 1990). Four other DnaA boxes were localized upstream from $h$ tr $A$ in a non-translatable region (cluster 3). All putative DnaA 
Table 3. DnaA box localization in the insert

Cluster 3 is localized upstream from the $h t r A$ gene. Clusters 2 and 1 are upstream and downstream from $d n a A$, respectively.

* refers to DnaA boxes on the complementary strand.

Consensus sequences were TTATC/ACACA on one strand and TGTGG/TATAA on the complementary strand. Lower case letters indicate a deviation from these consensus sequences.

\begin{tabular}{|lll|}
\hline Position & DnaA box sequence & Cluster \\
\hline 631 & TTATtCACA & 3 \\
686 & TTATCCACA & 3 \\
$698^{*}$ & TGTGTAaAA & 3 \\
$711^{*}$ & TGTGTtTAA & 3 \\
2755 & TTATCaACA & 2 \\
2806 & TTATCCACt & 2 \\
2858 & TTATCCCCA & 2 \\
$2870^{*}$ & TGTGGATAA & 2 \\
$2892^{*}$ & TGTGGATtA & 2 \\
$2913^{*}$ & TGTGGAaAA & 2 \\
$4351^{*}$ & TGTGGATAA & 1 \\
4380 & TTATCCACA & 1 \\
4435 & TTtTCCACA & 1 \\
\hline
\end{tabular}

boxes are listed in Table 3. In B. subtilis a DnaA box region is also located about $3 \mathrm{~kb}$ upstream from $d n a A$. Another common feature of bacterial replication origins are AT-rich regions adjacent to DnaA boxes. These regions have been identified. This argues for the localization of the replication origin of S. pneumoniae near any one of the three clusters of DnaA boxes.

\section{Gene organization around dnaA}

Fig. 3 shows the genes and their organization in the $6 \mathrm{~kb}$ fragment containing the $d n a A$ gene. The first nucleotides on the left of this insert (1-71) are identical to a pneumococcal sequence reported by Pestova et al. (1996) who designated it as a tRNA ${ }^{\mathrm{Arg}}$ gene. Only the last $2 \mathrm{nt}$ of the gene are missing. This gene is followed by orf $L$, also named orf1. Interestingly orf $L$ and $t R N A^{A r g}$ are preceded by the competence locus comCDE (Pestova $e t$ al., 1996; Cheng et al., 1997).

The gene immediately to the right of orf $L$ is a gene homologous to htrA of E. coli encoding a serine protease (Lipinska et al., 1989; Skorko-Glonek et al., 1995). The active site of this protease contains a serine residue, a histidine residue and an aspartate residue. The homology is especially striking around the active site (Bass $e t$ al., 1996).

Between $h \operatorname{tr} A$ and $d n a A$, separated by $216 \mathrm{bp}$, where DnaA boxes are found, a gene homologous to spo0J (Mysliwiec et al., 1991) has been identified. The identity between spoOJ of $B$. subtilis and $S$. pneumoniae is $42.9 \%$. This gene is required for the initiation of sporulation and for normal chromosome partitioning during vegetative growth in B. subtilis (Mysliwiec et al., (a)

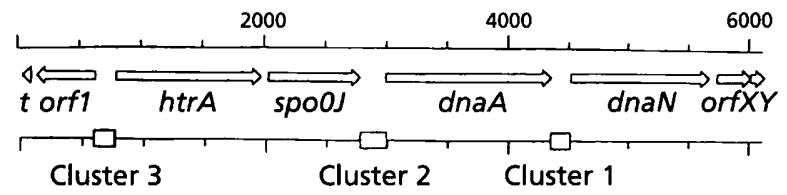

(b)

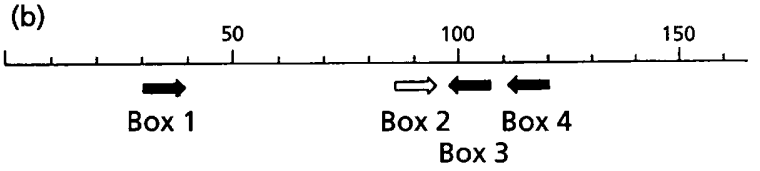

Cluster 3
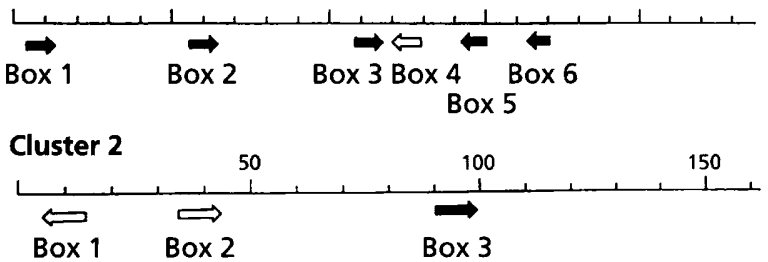

Cluster 1

Fig. 3. Gene organization of the $d$ naA region of S. pneumoniae strain R801. (a) Schematic representation of the ORFs deduced from the nucleotide sequence. The arrows indicate the $5^{\prime}-3^{\prime}$ direction. The open triangle $(t)$ represents the tRNA ${ }^{\mathrm{Arg}}$ gene. Boxes (on the second line) between arrows indicate nontranslatable regions containing clusters of multiple repeats of DnaA boxes. (b) Clusters of DnaA boxes. White arrows refer to consensus sequences TTAT(AVC)CACA or TGTG(G/T)ATAA; black arrows refer to DnaA box sequences that differ by one base from the consensus.

1991; Ireton et al., 1994; Lin et al., 1997; Glaser et al., 1997). It is likely that the spo0J product of $S$. pneumoniae, being a non-sporulating bacterium, is required for accurate chromosome partitioning. In B. subtilis, spo0J is also upstream from $d n a A$ but separated by 10 genes representing about $10 \mathrm{~kb}$. Another divergence is the direction of translation. In $S$. pneumoniae dna $A$ and spo0J have the same orientation, whereas they are opposite in B. subtilis.

A gene homologous to dnaN has been found downstream from $d n a A$ and DnaA box cluster 1 . The identity between dnaN of $B$. subtilis and $S$. pneumoniae is $42.3 \%$. The gene encodes the $\beta$ subunit of PollII, a component of the core enzyme. This organization of $d n a A$, DnaA boxes and $d n a N$ has been reported for several bacteria and the replication origin is often located upstream from this gene.

No significant homology was found by searching the databases with the amino acid sequence of the orf $X$ product. For orf $Y$ only a part of the sequence is known. The N-terminal sequence of its product is highly homologous to the corresponding part of a putative GTP-binding protein of $B$. subtilis called YyaF. In this organism the corresponding gene is localized upstream from $s p o 0 J$ and separated by about $5.7 \mathrm{~kb}$ containing three unknown proteins. 


\section{Conclusions}

In this study we have sequenced $6 \mathrm{~kb}$ of the $S$. pneumoniae genome that includes the $d n a A$ gene. We have found that this gene is surrounded by several DNA boxes and is adjacent to the $d n a N$ gene. As this organization is conserved in several bacteria (B. subtilis, Streptomyces coelicolor, P. putida and M. capricolum), we suggest that the origin of replication of the pneumococcal chromosome is also in this region. Another argument for this proposal is that AT-rich regions have been observed in this fragment. Computer analysis shows that there are 14 sequences of 20-33 nt containing more than $90 \%$ AT. They are dispersed in the fragment with a tendency to occur near DNA boxes. This is a common feature of a replication origin and might participate in the destabilization of the DNA helix.

However, organization around $d n a A$ is different in some bacteria such as Synechococcus sp., where dnaA and $d n a N$ are not adjacent (Richter \& Messer, 1995). The replication origin has been located near 11 DNA boxes upstream from dnaN (Liu \& Tsinoremas, 1996).

The organization of the genes around dnaA in Streptococcus pneumoniae shares some similarities with that of other bacteria but is itself unique.

Several genes were identified in this cloned fragment by their homology with known genes. A serine protease encoded by $h t r A$ has not been described previously in $S$. pneumoniae. Several reports suggest that serine proteases are important components of the pathogenic mechanisms of other intracellular micro-organisms (Johnson et al., 1991; Braun Breton \& Pereia da Silva, 1993; Cameron et al., 1994). It is quite possible that this serine protease is involved in $S$. pneumoniae virulence.

The occurrence of $s p o 0 \mathrm{~J}$ in a non-sporulating bacterium such as $S$. pneumoniae suggests that the function of this gene, reported to act either in sporulation or in septation in Bacillus subtilis, is primarily involved in the latter in $S$. pneumoniae. The proximity of the competence operon to the putative origin is noteworthy but its significance is unknown.

Localization of the putative origin of replication in the physical and genetic map of the chromosome will be useful for further studies on the molecular genetics of this pathogenic bacterium.

\section{ACKNOWLEDGEMENTS}

We thank Sandy Lacks for discussions and suggestions about the SD and promoter sequences of Streptococcus pneumoniae, and Bernard Martin for the generous gift of the $\lambda$ Zap bank.

\section{REFERENCES}

Bass, S., Gu, Q. \& Christen, A. (1996). Multicopy suppressors of Prc mutant Escherichia coli include two HtrA (DegP) protease homologs (HhoAB), DksA, and a truncated R1pa. J Bacteriol 178, 1154-1161.

Braun Breton, C. \& Pereia da Silva, L. H. (1993). Malarial proteases and red blood cell invasion. Parasitol Today 9, 92-96.
Cameron, R. M., Stevenson, K., Inglis, H. F., Klausen, J. \& Sharp, J. M. (1994). Identification and characterization of a putative serine protease expressed in vivo by Mycobacterium avium subsp. paratuberculosis. Microbiology 140, 1977-1982.

Chen, H., Bjerknes, M., Kumar, R. \& Jay, E. (1994). Determination of the optimal aligned spacing between the Shine-Dalgarno sequence and the translation initiation codon of Escherichia coli mRNAs. Nucleic Acids Res 22, 4953-4957.

Cheng, Q., Campbell, E. A., Naughton, A. M., Johnson, S. \& Masure, H. R. (1997). The com locus controls genetic transformation in Streptococcus pneumoniae. Mol Microbiol 23, 683-692.

Claverys, J. P., Roger, M. \& Sicard, A. M. (1980). Excision and repair of mismatched base pairs in transformation of Streptococcus pneumoniae. Mol Gen Genet 178, 191-201.

Fujita, M. Q., Yoshikawa, H. \& Ogasawara, N. (1989). Structure of the $d n a A$ region of Pseudomonas putida : conservation among three bacteria, Bacillus subtilis, Escherichia coli and Pseudomonas putida. Mol Gen Genet 215, 381-387.

Fujita, M. Q., Yoshikawa, H. \& Ogasawara, N. (1990). Structure of the dnaA region of Micrococcus luteus: conservation and variations among eubacteria. Gene 93, 73-78.

Fujita, M. Q., Yoshikawa, H. \& Ogasawara, N. (1992). Structure of the $d n a A$ and $d n a A$-box region in the Mycoplasma capricolum chromosome: conservation and variations in the course of evolution. Gene 110, 17-23.

Fuller, R. S., Funnel, B. E. \& Kornberg, A. (1984). The DnaA protein complex with the $E$. coli chromosomal replication origin (oriC) and other DNA sites. Cell 38, 889-890.

Gasc, A.-M., Kauc, L., Baraillé, P., Sicard, M. \& Goodgal, S. (1991). Gene localization, size and physical map of the chromosome of Streptococcus pneumoniae. J Bacteriol 173, 307-312.

Gasc, A.-M., Geslin, P. \& Sicard, A. M. (1995). Relatedness of penicillin-resistant Streptococcus pneumoniae serogroup 9 strains from France and Spain. Microbiology 141, 623-627.

Glaser, P., Sharpe, M. E., Raether, B., Perego, M., Ohisen, K. \& Errington, J. (1997). Dynamic, mitotic-like behavior of a bacterial protein required for accurate chromosome partitioning. Genes Dev 11, 1160-1168.

Johnson, K., Charles, I., Dougan, G., Pickard, D., O'Gaora, P., Costa, G., Ali, T., Miller, I. \& Hormaeche, C. (1991). The role of a stress-response protein in Salmonella typhimurium virulence. Mol Microbiol 5, 401-407.

Ireton, K., Gunther, N. W., 4th \& Grossman, A. D. (1994). spooJ is required for normal chromosome segregation as well as the initiation of sporulation in Bacillus subtilis. J Bacteriol 176, 5320-5329.

Kauc, L., Mitchell, M. \& Goodgal, S. H. (1989). Size and physical map of the chromosome of Haemophilus influenzae. J Bacteriol $171,2472-2479$.

Lefèvre, J. C., Claverys, J. P. \& Sicard, A. M. (1979). Donor deoxyribonucleic acid length and marker effect in pneumococcal transformation. J Bacteriol 138, 80-86.

Lin, D. C. H., Levin, P. A. \& Grossman, A. D. (1997). Bipolar localization of a chromosome partition protein in Bacillus subtilis. Proc Natl Acad Sci USA 94, 4721-4726.

Lipinska, B., Fayet, O., Baird, L. \& Georgopoulos, C. (1989). Identification, characterization, and mapping of the Escherichia coli htrA gene, whose product is essential for bacterial growth only at elevated temperatures. J Bacteriol 171, 1574-1584.

Liu, Y. \& Tsinoremas, N. F. (1996). An unusual gene arrangement for the putative chromosome replication origin and circadian 
expression of dnaN in Synechococcus sp. strain PC7942. Gene 172, 105-109.

Martin, B., Prats, H. \& Claverys, J. P. (1985). Cloning of the hexA mismatch repair of Streptococcus pneumoniae and identification of the product. Gene 34, 293-303.

Mysliwiec, T. H., Errington, J., Vaidya, A. B. \& Bramucci, M. G. (1991). The Bacillus subtilis spo0J gene: evidence for involvement in catabolite repression of sporulation. J Bacteriol 173, 1911-1919.

Ogasawara, N. \& Yoshikawa, H. (1992). Genes and their organization in the replication origin region of the bacterial chromosome. Mol Microbiol 6, 629-634.

Ogasawara, N., Moriya, S., von Meyenburg, K., Hansen, F. G. \& Yoshikawa, H. (1985). Conservation of genes and their organization in the chromosomal replication origin region of Bacillus subtilis and Escherichia coli. EMBO J 4, 3345-3350.

Ogasawara, N., Fujita, M. Q., Moriya, S., Fukuoka, T., Hirano, M. \& Yoshikawa, H. (1990). Comparative anatomy of oriC of eubacteria. In The Bacterial Chromosome, pp. 287-298. Edited by M. Riley \& K. Drlica. Washington, DC: American Society for Microbiology.

Ogasawara, N., Nakai, S. \& Yoshikawa, H. (1994). Systematic sequencing of the 180 kilobase region of the Bacillus subtilis chromosome containing the replication origin. DNA Res 1, 1-14.

Pestova, E. V., Havarstein, L. S. \& Morrison, D. A. (1996). Regulation of competence for genetic transformation in Streptococcus pneumoniae by an auto-induced peptide pheromone and a twocomponent regulatory system. Mol Microbiol 21, 853-862.

Richter, S. \& Messer, W. (1995). Genetic structure of the dnaA region of the cyanobacterium Synechocystis sp. strain PCC6803. $J$ Bacteriol 177, 4245-4251.

Roth, A. \& Messer, W. (1995). The DNA binding domain of initiator protein DnaA. EMBO J 14, 2106-2111.

Sabelnikov, A. G., Greenberg, B. \& Lacks, S. A. (1995). An extended -10 promoter alone directs transcription of the DpnII operon of Streptococcus pneumoniae. J Mol Biol 250, 144-155.

Salazar, L., Fsihi, H., de Rossi, E., Riccardi, G., Rios, C., Cole, S. T. \& Takiff, H. E. (1996). Organization of the origins of replication of the chromosomes of Mycobacterium smegmatis, Mycobacterium leprae and Mycobacterium tuberculosis and isolation of a functional origin from M. smegmatis. Mol Microbiol 20, 283-293.
Sambrook, J., Fritsch, E. F. \& Maniatis, T. (1989). Molecular Cloning: a Laboratory Manual, 2nd edn. Cold Spring Harbor, NY: Cold Spring Harbor Laboratory.

Schaefer, C. \& Messer, W. (1991). DnaA protein/DNA interaction. Modulation of the recognition sequence. Mol Gen Genet 226, $34-40$.

Schaper, S. \& Messer, W. (1995). Interaction of the initiator protein DnaA of Escherichia coli with its DNA target. $J$ Biol Chem 270, 17622-17626.

Schaper, S. \& Messer, W. (1997). Prediction of the structure of the replication initiator protein DnaA. Proteins Struct Funct Genet 28, 1-9.

Shine, J. \& Dalgarno, L. (1974). The 3'-terminal sequence of Escherichia coli $16 \mathrm{~S}$ ribosomal RNA: complementarity to nonsense triplets and ribosome-binding sites. Proc Natl Acad Sci USA 71, 1342-1346.

Short, J. M., Fernandez, J. M., Jorge, J. A. \& Huse, W. D. (1988). $\lambda$ Zap: a bacteriophage $\lambda$ expression vector with in vivo excision properties. Nucleic Acids Res 16, 7583-7600.

Singer, B. S., Gold, L., Shinedling, S. T., Colkitt, M., Hunter, L. R., Pribnow, D. \& Nelson, M. A. (1981). Analysis in vivo of translational mutants of the rIIB cistron of bacteriophage T4. J Mol Biol 149, 405-432.

Skorko-Glonek, J., Wawrzynow, A., Krzewski, K., Kurpierz, K. \& Lipinska, B. (1995). Site-directed mutagenesis of the HtrA (DegP) serine protease, whose proteolytic activity is indispensable for Escherichia coli survival at high temperatures. Gene 163, 47-52.

Southern, E. M. (1975). Detection of specific sequences among DNA fragments separated by gel electrophoresis. J Mol Biol 98, 503-517.

Yoshikawa, H. \& Ogasawara, N. (1991). Structure and function of DnaA and the DnaA box in eubacteria : evolutionary relationships of bacterial replication origins. Mol Microbiol 5, 2589-2597.

Zweiger, C. \& Shapiro, L. (1994). Expression of Caulobacter dnaA as a function of the cell cycle. J Bacteriol 176, 401-408.

Received 24 July 1997; revised 5 September 1997; accepted 6 October 1997. 